\title{
IDENTITY, AFFECT, AND CULTURAL CITIZENSHIP IN DIASPORIC CONTEXT
}

\author{
Shilpi Saxena and Diksha Sharma
}

Thapar Institute of Engineering and Technology

\begin{abstract}
Over the years, the study of transnational affect and emotion has become an emergent field of migrant narratives. Drawing on the notion of affect as a useful paradigm for analyzing emotional or bodily responses, the present article explores the affective and emotional dimensions of migration in connection with the emerging paradigm of 'cultural citizenship', which plays a crucial role in the construction of diasporic affiliations. In doing so, it provides new cartographies of mapping the emotional geographies of migration that are crucial to the understanding of the nature, intensity and affect of the migratory experience. Examining the nexus between emotion and migration, this article explores the cultural dimension of citizenship, and how cultural acts and practices that immigrants employ provide new forms of belonging and identification in relation to increasingly complex patterns of transnational migration.
\end{abstract}

Keywords: migration, home, belonging, affect, citizenship

DOI: https//doi.org/10.3176/tr.2022.1.02

Received 20 August 2021, accepted 23 September 2021, printed and available online 10 March 2022

\section{Cultural citizenship - an introduction}

Over the past few decades, a massive and diversified system of migration has emerged and developed on different levels: national, regional, and global, resulting in the expansion and acceleration of cross-border interactions. Although transnational migration is not altogether a new phenomenon, it has connected different cultures and communities, which further leads to immigrants' dilemma of negotiating home, 
belonging, and membership within nation-states. It is therefore worth exploring a range of pressing questions - the relationship between collective and individual, social and political, difference and democracy, culture and nation that seeks to intervene in current debates on citizenship.

Within the context of increased cultural diversity and globalization, the concept of 'cultural citizenship' has emerged as an interdisciplinary concept that emphasizes the right of the minorities to be different and to be respected as such, without revoking their rights of membership or belonging to the participatory community (Rosaldo 1994, Rosen 1997). In this sense, the cultural understanding of citizenship is concerned not only with the struggle for legal and political rights, but crucially with recognition, respect and visibility for a wide range of cultural practices. What becomes defining here is a call for cultural respect or in the words of Miller, "the positive acknowledgment of difference in and by the mainstream' (2001: 2). This mediated dimension of citizenship that is central to the struggles for recognition and difference is appropriate for cosmopolitan societies. However, this intervention is in no way utopian, nor does it celebrate culture as a quick-fix solution for the concerns associated with the notions of home, nation, identity and belonging. Instead, it focuses on how cultural citizenship that migrants create through participation, performances, and allegiances facilitates and offers new possibilities for diasporic affiliations. In contrast to the conventional notion of citizenship that frames national identity within neatly bounded spatial boundaries, the concept of cultural citizenship offers a relatively flexible framework for dealing with the questions of home and belonging, thus shifting focus from the fixity of 'roots' and 'origins' to the fluidity of 'routes' and 'itineraries'. It is within the context of these shifting patterns of diaspora narratives that the present study is located.

Addressing the relationship between cultural identity and citizenship, it explores the affective dimensions of migration, home, and belonging, so as to provide a deeper understanding of human predicaments in a mobile world. It attempts to pursue two critical questions: First, how shifting sociopolitical contexts affect migrants' life and how they respond to their shifting circumstances; Second, how various emotional cultural practices that migrants deploy to perform citizenship provide new forms of affective relations and belonging in relation to increasingly complex patterns of localization and globalization. In particular, it demonstrates that a focus on cultural questions and their relation to citizenship is central in an era dominated by popular forms of culture and complicated by postcoloniality and postmodernity. By seeking to examine citizenship in a new perspective, this paper also explores the postcolonial affect in terms of colonial residue, spatial dispersion and identity crisis and how citizenship practices facilitate migrants in sustaining bonds and keeping in touch transnationally. 


\section{Emotional geographies of home and belonging}

In much of the diasporic narratives like 'Beauty and the Beast', 'A Wicked Old Woman', 'The Coral Strand', and 'Dynamite' authored by Ravinder Randhawa' an Asian Diasporic author reflected the concept of home, an evocative notion, which further opens up venues for questions pertaining to race, ethnicity, country of origin, documents and citizenship, nationality. 'Where do you belong to?' or 'Where are you really from?', such naïve questions that are always laden and definitional in some way induce emotions, intimacy and feelings that play a major role not just in creating 'sustained ties with peoples and institutions across the borders but also in constructing the idea of diasporic belonging. Despite the conceptional rise of transnationalism, the nexus between emotions and migration has not been explored in detail, especially not within the migrant and diaspora literature.

However, there has been a growing interest in studying the nature of emotions, affects, feelings and sentiments over the last decade. The existing research on the emotionality of migration has highlighted the critical role of emotions and affect in comprehending the dynamics of home, identity, and belonging. (Ahmed 2004, Anthias 2006, Yuval-Davis 2006, Röttger-Rössler 2018, Wise and Velayutham 2017, Houen 2020). This renewed focus on the role of emotions, affects and feelings in migration sheds light on how the notion of transnational affect and emotion is instrumental in understanding the experience and impact of migration, as well as in understanding the shifting contours of modern citizenship. It is therefore worth examining the affective and emotional dimensions of home and belonging in connection with the emerging paradigm of 'cultural citizenship' which plays a crucial role in the construction and formation of diasporic affiliations. This article extends the research by exploring cultural citizenship as a process that needs to be rethought and reformulated as a site of multilocality that opens up opportunities for diaspora to negotiate complexities of diasporic formations and to form multi-local dwelling, roots, and belongings. The study contributes to the growing scholarship on affective migration by examining tangible effects of emotions at play in such spaces: in particular, shame, pride, loss, ambivalence, homesickness and alienness in an identity that is inextricably related to the ancestral homeland, and which may be leading to the disruption of belonging among diaspora.

\section{Reflection of identity and cultural citizenship in diasporic context}

When studying processes of migration from an emotional perspective, the notion of belonging has emerged as a dominant lens through which to explore the personal and social dynamics which influence migrants' ability to develop a sense of affiliation in their receiving society. However, this notion takes on complicated twists for second-generation immigrants:

1 See the Ravinder Randhawa's official website $<$ https://www.ravinderrandhawa.com/ $>$. Accessed on 12 January 2022. 
We are different from our parents. We have another history, and other values and ideas about living in Germany. They are the foreigners, not us. But we are still far from being German. So what are we then? What do we want to be? (Bota et al. 2012: 10; translated and quoted in Röttger-Rössler 2018).

The above quoted excerpts from Wir neuen Deutschen [We new Germans] explicitly articulate the core concern of this paper: the emotional valence of belonging and affiliation. The affective tensions illustrated here find an expression in different forms in all Randhawa's narratives. One of the narratives named Beauty and the Beast (2014) is taken as case study here, wherein she explores the complexity of being second-generation immigrants (new generation British Asians): what it means to grow up and live in Britain as second-generation youth; what are the emotional costs of being embedded in multiple and transnational spaces? In highlighting the transnational struggles of young generation immigrants, Randhawa focuses on the ambivalence and ambiguities associated with the physical space the diaspora inhabit, as well as the affective space they strive to connect with. Randhawa was born in India and grew up in Warwickshire, now lives in London. She is an acclaimed author and blogger at Huffington Post. She is highly involved in helping Asian women suffering domestic abuse, and in anti-racist movements. She is also the founder of The Asian Women Writers Workshop (later known as the Asian Women Writer's Collective), which published two major collections: Right of Way (1989) and Flaming Spirit (1994).

Being a second-generation immigrant, Randhawa's protagonist, Harjinder confronts enormous emotional and affective challenges while negotiating her Punjabi-British hyphenated identity. Harjinder's mother is quite aware of her daughter's inner conflict, as can be seen in the novel where her mother explains the conflicting challenges of the South Asian diaspora:

'It must be difficult living in England, yet being Indian.' ... 'It must be hard to um...negotiate between the two'... You know what it's like as soon as you step out of that door. It's like having to struggle through a fog of racism. Sometimes it hits you bang in the face. Sometimes it's thin and vague, other times it's like everything is clear and shiny, and then it comes again, bang, smack, wallop.' 'you'd better learn how to be strong' (15).

This excerpt clearly reveals how complex negotiations between the two cultures coupled with entrenched racism may affect the younger South Asian diaspora's sense of place and self. It is indeed this sense of place - not solely the physical dwelling space but at times the psychological and emotional ones - that triggers Harjinder's sense of cultural alienness and unhomeliness. Despite Harjinder's efforts to integrate into British society, she experiences the feelings of non-belonging and uprootedness. While struggling to claim a sense of place and self, she realizes that everyone else except her has its own space in the world. Even a box of vegetable has a secure place: 
This was my quality time, to stand and stare. When I can, that is, inbetween picking up suspicious looks, getting pushed, jostled and being moved on by the shopkeeper who was putting out his boxes of vegetables. They took up half the pavement and no-one pushed them around. Even they have a place in the world, I thought jealously. Me? I'm a wog, a female. An unwanted Brit-Cit. An unwanted daughter (106).

This existential paradox experienced by Harjinder calls attention to the 'lived tension' (Clifford 1994: 255), the affective dimension of living in transnational and translocational social constellations. This in-betweenness - a condition akin to third space (Bhabha 1994) and much like Trishanku, a metaphor proposed by Uma Parmeswaran (1998) - is often experienced by second-generation immigrants, as they navigate the cultural codes of parents and family on the one hand, and mainstream British culture on the other. For Harjinder, the ignorance of native culture, the lack of knowledge about one's home nation, culture, roots, results in a feeling of ambivalence and ambiguity. With the advent of media and technology, however, it is becoming increasingly less of a challenge provided that immigrants use modern technology (Facebook, Whats App, Twitter,) to connect to their home culture. Nevertheless, immigrants' lack of physical ties with their ancestral homeland becomes a significant cause of their uprootedness. For such individuals, homeland becomes a place of imagination, virtually conjured, never visited, as Harjinder describes India as 'the unknown... the unfulfilled, lonely part' (Randhawa 2014: 69) of herself. These lines reveal the meaning of spatial and material aspects for affective self-positioning and show how the feeling of alienation ensuing from unfamiliar spaces and objects may thwart the feelings of belonging and affiliation to a social and cultural community.

This affective ambivalence of the contested spaces that all diasporas inhabit is further reflected in Harjinder's Muslim friend, Gazala who is also caught between the ever-shifting boundaries of the local and the transnational. Through her character, Randhawa brings into focus the profound affective tensions that accompany the lives of Muslim diaspora. The author candidly reflects on her predicament by articulating her thoughts:

One look at me and the whole world knows what I am. Or think they do - 'fundamentalist, extremist, frightening ...' You think it's easy to walk down the street, go into a shop...to go off for my prayers with everyone looking and sniggering (36).

Due to her traditional Islamic background, she is trapped in an immediate and sustained environment of 'otherness' in which her race, color and religion is uncanny and out of place. Her hijab ${ }^{2}$ and $a b a y a^{3}$, as a signifier of her Muslim lineage not only makes her an object of derision within the cultural landscape of British society but also triggers the emotions of shame, guilt and inferiority. Through this insightful depiction of Ghazala's predicament, Randhawa reveals how the feeling of shame in

\footnotetext{
2 hijab-headscarf generally worn by Muslim women.

3 abaya - a full-length gown generally worn by Muslim women.
} 
relation to one's race, religion and homeland may erase the manifestations of pride, while also implying a sense that there is something to be ashamed of the culture and identity that it provides. Gazala's cultural identity - the physical signifier of radical otherness - renders her susceptible to prejudice and stereotypes even from her friend Harjinder who is skeptical of Gazzy's intensions of organizing a Diwali party, 'What's a Muslim doing organizing a Hindu festival?' (95). Harjinder's words are like thrusting a pebble into the pond of Gazala's consciousness - the gesture produced reverberations consistent with Islamic fundamentalism. What is more, such stereotypes point to the way how a particular ethnic religion is seen internationally or especially here in Britain.

Of interest here are the emotional responses that such gestures or stereotypes elicit and the ensuing affective tension that can result in an intense sensitivity to the shaming of the nation as well as of race. Aside from fostering a sense of shame, guilt, and inferiority, such negative stereotypes affect Gazala's identity and self-esteem, preventing her from creating a sense of belonging and 'being-at-home' in Britain. It is this condition of unbelonging arising from Gazala's experience of racist prejudice in Britain that Randhawa brings to the fore in the narrative. Although Gazala is a British citizen, her skin tone, her hijab and abaya, the 'visible' markers of her cultural difference fix her identity as an extremist, fundamentalist, racial other in dominant-white Britain and exclude her from the definition of Britishness. As a quintessential liminal Briton, she faces continuous challenge to her existence, as expressed in her own words, 'I feel like I'm in new territory, so I can't depend on anything' (34-35). These lines adequately articulate the complex realities of the new generation Britons' everyday experience of living in Britain. Regardless of their family background, what unites the second-generation immigrants like Harjinder and Gazala, is the fragility and ambivalence of their affiliation to Britain and the resulting feeling of unbelonging.

In contrast to Hari-jan, Randhawa represents Suresh Robinson, Harjinder's classmate/boyfriend, whose mother Laxmi has inculcated Indian culture and traditions in him all the while making sure that he 'speaks fluent Hindi, can read and write it' and 'is perfectly at home in India' (83-84). Furthermore, Suresh's prowess in Bhangra ${ }^{4}$ at Diwali ${ }^{5}$ party makes Harjinder realize that unlike her, many new generation Britons are very much in touch with their parents' roots, culture and traditions. Despite being a mixed-race adolescent, Suresh is rooted to Punjabi culture and expresses greater transnational loyalties than Hari-jan. It is this ease with his Punjabi roots and culture that elicits emotional responses of pride in Suresh and enables him to build a strong sense of personal and social confidence. The feeling of rootedness leaves no room for ambivalence or existential void, thus leading to higher self-esteem, motivation and aspiration in him. In order to find a sense of home, security and comfort, he adopts a transnational identity that redefines the notions of home and belonging and builds up new ways of understanding and negotiating these concepts.

\footnotetext{
${ }^{4}$ Bhangra-folk dance and music of the Punjab.

5 Diwali-a Festival of Light. The celebration of Ram's return from exile.
} 


\section{Cultural citizenship as a site of multilocality}

With increasing globalization and transnational migration, notions of home, belonging and affiliation take on complicated twists and turns for immigrants, thereby shaping the contours of modern-day citizenship. Such immigrants who are continuously engaged in negotiating the tension of assimilation and transnationalism create emotional geographies of belonging by employing a different version of citizenship or what Rosaldo theorizes as 'cultural citizenship'. This mediated dimension of citizenship that is rooted not in the 'nation-states' but in 'culture' (Cho 2007: 468) is a potential site for political contestation, an expression of resistance to oppression and exclusion. A renewed focus upon the cultural dimension of citizenship sheds light on how the contested national space can be negotiated through cultural productions and cultural acts, and how such cultural practices allow for the performance of home, identity, and belonging within such spaces. In this sense, cultural citizenship as performance allows immigrants to reclaim identity and belonging within nation(s) and transnational communities through various cultural practices which include but are not limited to:

literature, film, Satellite TV shows, Bollywood, photography, dance, music, performance arts, languages, folklores, cultural myths, rituals, religious texts, newspapers, independent community press, Internet blogs and websites, collectables and souvenirs, [everyday cultural gestures] and so on (Hua 2011).

These forms of mediation are thus socially and politically relevant tools that facilitate immigrants in maintaining a sense of community and belonging both within and beyond the space of the nation-states. For such individuals, home then is not solely about roots or nostalgia but at times more of a feeling of safety or security within a community of shared values, networks, and practices (Anthias 2006: 21). It is indeed these common affiliations, interests and affinities that construct an affective diasporic belonging, where the overcoming of loss, uprootedness and unbelonging is contiguous with new forms of 'longing' that become 'belonging' (Appadurai as quoted in Ponzanesi 2020). This is also reflected in the novel examined in the present study, where new generation Britons, Harjinder, Gazala and Suresh redefine the boundaries of citizenship and membership through these emotional cultural practices, sustaining long-distance relationships and claiming multiple modes of belonging. As illustrated in the narrative through the character of Suresh, who maintains emotional connections to distant family through his frequent trips to India as well as through Indian music, film and television serials or what Arjun Appadurai refers to as 'mediascape' and Sandra Ponzanesi theorizes as 'diasporic digitality' (2020). The use of digital media allows diasporic subjects and communities to keep in touch with their native culture and native lands, thus strengthening their ethnic ties and sense of rootedness. While Suresh watches Hindi classic films, like Pyaasa, and popular television soaps in India in the late 1980s like Nukurdh, his mother, Laxmi 
wears $\mathrm{Khadi}^{6}$, as a way to maintain their cultural identity and preserve their ethnicity. In a discussion with her friend Manjit, Laxmi affirms that her decision to wear Khadi is her chosen way of life, or in Judith Butler's (1988) terms, 'a performative act' of constituting identity and belonging:

[So] I vowed I would always wear khadi as my... as my... as a way of showing that I won't become foreign. So I got married in khadi. Manjit, you can't imagine the scandal!' laughing gleefully. 'The scandal wasn't that I was marrying a white man, but that I was getting married in khadi (1987 83).

The above extract serves to illustrate how diasporic subjects and communities perform identities and citizenships through various cultural practices to reclaim belonging and affiliation within and across national borders. Furthermore, it also brings into focus how emotions are channelized and reformatted as transmittable that allows migratory/diasporic subjects to create 'diasporic communities of belonging' (Slade 2014) and to rewrite their citizenship status within the nation-state. In this respect, the performance of cultural citizenship facilitates individuals like Suresh and Laxmi to construct 'homes away from home' and claim multiple modes of identity and belonging.

These acts of double or multiple affiliation, Randhawa suggests, is not a question of facility or availability of option, but a chosen way of life even for her main character, Harjinder who transcends social, cultural and national boundaries by choosing to speak a 'lovely mixture of Hindi, Panjabi and English' (63) and wearing Reebok shoes with shalwar-kameez. ${ }^{7}$ By shifting codes and languages, she learns to manage ambivalence and develops new modes of identification and belonging- all of which make it easier for her to feel accepted, safe and anchored within dominant white culture. What is more, the reference to classic Hindi movie Pyaasa, and its music '...udaas raat hai ... zuban pe dard...' (107) provides a romantic background to the narrative, bringing Hari-jan closer to her future boyfriend, Suresh. Thus, for Hari-jan, finding a link to the Bollywood movies and music loving side of her is like finding herself, the other 'me' that had lain trapped, in exile' or a 'homecoming' (108) which she cannot describe but experiences while falling in love with Suresh.

Furthermore, the celebration of Diwali, and Bhangra dance performance arranged by Hari-jan, Gazala, and their multi-cultural group, facilitate not only first-generation immigrants but also new generation Britons in preserving a feeling of rootedness and fostering a sense of being-at-home in Britain. Through these affective and emotional ritual performances, Randhawa underscores how festivals, dance, music take on cultural significance and becomes a way to anchor rootless identity. At the same time, it focuses on and how the sense of place and self is affectively conveyed through such emotional forms of mediation. In the same way, the 'Beauty contest' held in Hari-jan's school offers new possibilities for diasporic affiliations, while creating a

${ }^{6}$ Khadi-hand spun cotton material.

7 shalwar-kameez - Indian outfit consisting of tunic, complementary trousers and scarf. 
site for new forms of activism and for raising awareness about social change. Rather than commodifying participants and their bodies in the name of a social cause, this beauty pageant allows them to share their personal experiences in such a way as to build their self-esteem and a sense of collective identity and solidarity.

Like Suresh, and Harjinder, Gazala also makes sincere efforts to navigate her affective ambivalence stemming from existential void, through multilocal roots, homes and affiliations. She adopts a transnational identity that develops in her a sense of being anchored and integrated in a predominantly white society. This is illustrated through Gazala's modern clothing sense at the Diwali party where she surprises everyone by wearing a long multi-layered gown with golden leggings, and a super-stylish scarf around her head. By donning a traditional dress in a hybrid way, she not only liberates herself from the normative and traditional constraints, but also redefines the conventional notion of identity. In this sense, for Randhawa's characters, like Laxmi, Harjinder, and Gazala, dressing oneself is both an act of fashioning the self as well as an act of 'ethnic performativity' (Butler 1990, 1993) through which they learn to manage the spatiality of everyday life effectively while staking claims to multiple modes of identity and belonging. Thus, by retaining sociopolitical membership to the nation as well as to transnational communities, they rewrite their citizenship status, while 'creating new forms of affective relations and belonging' (Alinejad and Olivieri 2020). The notion of postcolonial spatiality thus takes on a different dimension by the intervention of cultural citizenship that pertains to different cultural practices and performative acts.

\section{Conclusion}

The present article has brought to the fore the emotional processes of nonrecognition and rootlessness affecting immigrants in the context of globalization and localization, thus contributing to the ongoing debates about the emotional geographies of transnational migration. By invoking the affective dimension of home and belonging in diasporic fiction, it suggests that any efforts to re-build social bonds will require attention to cultural dimensions of citizenship that not only allows immigrants to be at home in Britain but also provides them a way to anchor their rootless identity. It also focuses on how cultural citizenship that immigrants create through participation, performances, and allegiances offers new possibilities for diasporic affiliations, allowing for the creation of new ways of doing and being in the world. As a site of multilocality, it is a new mode of identification and membership where the 'right to be different' is pursued. A renewed stress upon the cultural dimension of citizenship sheds light on how distance can be bridged through cultural productions and cultural acts, and how such cultural practices help migratory subjects in negotiating and redefining their citizenship status to the nation(s) as well as transnational communities.

The notions of home, belonging and affiliation are thus remediated through new forms of emotional cultural practices that allow diasporic/migratory subjects to 
affirm their relations with homeland and to create new connections within and across diasporic communities through multiple affiliations and interventions provided by such acts. The sense of 'emotional security' and 'being anchored' allowed by cultural acts or performances have changed the way in which migration is experienced and modes of self-identification, belonging and citizenship are mediated. The notion of affect and emotion thus takes a different dimension by integrating into the context of postcolonial/diasporic literature, an aspect of critical writing in need of more scholarly attention.

Address:

Shilpi Saxena

School of Humanities and Social Sciences,

Thapar Institute of Engineering and Technology Patiala,

Punjab, India - 147004

Tel.: +8195049368

E-mail: shilpi.saxena@thapar.edu

Diksha Sharma

School of Humanities and Social Sciences,

Thapar Institute of Engineering and Technology Patiala,

Punjab, India - 147004

E-mail: diksha.sharma@thapar.edu

\section{References}

Ahmed, Sara (2004) Cultural politics of emotion. New York: Routledge.

Alinejad, Donya and Domitilla Olivieri (2020) “Affect, emotions and feelings". In Kevin Smets, Koen

Leurs, Myria Georgiou, Saskia Witteborn, and Radhika Gajjala, eds. Handbook of media \& migration, 64-73. London: Sage.

Anthias, Floya (2006) "Belongings in a globalising and unequal world: rethinking translocations".

In Nira Yuval-Davis, Kalpana Kannabiran, and Ulrike Vieten, eds. The situated politics of belonging, 17-31. London and Thousand Oaks, CA: Sage.

Appadurai, Arjun (2020) "Traumatic exit, identity narratives, and the ethics of hospitality". Television and New Media 20, 6, 558-565.

Bhabha, Homi K. (1994) The location of culture. London and New York: Routledge.

Bota, Alice, Khuê Pham, and Özlem Topçu (2012) Wir neuen Deutschen: wer wir sind, was wir wollen.

Reinbek bei Hamburg: Rowohlt.

Butler, Judith (1988) "Performance acts and gender constitution: an essay in phenomenology and feminist criticism". Theatre Journal 40, 4, 519-531.

Butler, Judith (1990) Gender trouble. New York: Routledge.

Butler, Judith (1993) Bodies that matter: on the discursive limits of 'sex'. New York: Routledge. 
Cho, L. (2007) "Diasporic citizenship: inhabiting contradictions and challenging exclusions". American Quarterly 59, 2, 467-478.

Clifford, James (1997) Routes: travel and translations in the late twentieth century. Cambridge, Mass. and London: Harvard University Press.

Houen, Alex (2020) Affect and literature. Cambridge: Cambridge University Press.

Hua, Anh (2011) "Homing desire, cultural citizenship, and diasporic imaginings". Journal of International Women's Studies 12, 4, 45-56.

Miller, Toby (2001) “Introducing... cultural citizenship”. Social Text 19, 4, 1-5.

Ong, Aihwa, Virginia R. Dominguez, Jonathan Friedman, Nina Glick Schiller, Verena Stolcke, David Y.

$\mathrm{H}$. Wu, and Hu Ying (1996) "Cultural citizenship as subject-making: immigrants negotiate racial and cultural boundaries in the United States" [and comments and reply]. Current Anthropology $37,5,737-762$.

Parameswaran, Uma (1998) Trishanku and other writings. New Delhi: Prestige Books.

Ponzanesi, Sandra (2020) "Digital diasporas: postcoloniality, media and affect". Interventions 22, 8, 977-993.

Rosaldo, R. (1994) “Cultural citizenship and educational democracy”. Cultural Anthropology 9, 3, 402-411.

Rosen, Lawrence (1997) "The right to be different: indigenous peoples and the quest for a unified theory". The Yale Law Journal 107, 1, 227-259.

Röttger-Rössler, Birgitt (2018) "Multiple belongings: on the affective dimensions of migration". Zeitschrift für Ethnologie 143, 2, 237-262.

Slade, Christina (2014) Watching Arabic television in Europe: from diaspora to hybrid citizens. Basingstoke: Palgrave Macmillan.

Yuval-Davis, N. (2006) "Belonging and the politics of belonging". Patterns of Prejudice 40, 3, 197214.

Wise, Amanda and Selvaraj Velayutham (2017) "Transnational affect and emotion in migration research”. International Journal of Sociology 47, 2, 116-130.

Witteborn, S. (2014) "Forced migrants, emotive practice and digital heterotopias". Crossings: Journal of Migration \& Culture 5, 1, 73-85. 